\title{
Decrease in Brain Distribution of Fluvoxamine in Experimental Hyperlipidemic Rats
}

\author{
Keizo Fukushima ${ }^{1}$, Shinji Kobuchi ${ }^{2}$, Masakazu Shibata $^{2}$, Kanji Takada $^{2}$, and Nobuyuki Sugioka ${ }^{1}$ \\ ${ }^{1}$ Department of Clinical Pharmacokinetics, Faculty of Pharmaceutical Sciences, Kobe Gakuin University, Hyogo, Japan. \\ ${ }^{2}$ Department of Pharmacokinetics, Kyoto Pharmaceutical University, Kyoto, Japan.
}

Received, June 19, 2011; Revised, July 31, 2011; Accepted, October 25, 2011; Published, October 26, 2011.

\begin{abstract}
Purpose. Many clinical reports and trials have suggested that fluvoxamine (FLV) reduces plasma lipoprotein levels. However, few studies have reported the effect of plasma lipoproteins on FLV pharmacokinetics. The aim of the present study was to investigate the affinities of FLV to plasma lipoproteins and the effect of plasma lipoproteins on the biodistribution of FLV using an experimental hyperlipidemic (HL) rat model. Methods. HL rats were prepared by intraperitoneal administration of Poloxamer-407 solution $(1.0 \mathrm{~g} / \mathrm{kg})$. In vitro protein binding and distribution of FLV in plasma lipoproteins were determined in control and HL rats. In vivo pharmacokinetic study (intravenous administration of FLV, $5.0 \mathrm{mg} / \mathrm{kg}$ ) and biodistribution analysis for brain and liver at a steady state (infusion, $1.5 \mathrm{mg} / \mathrm{kg} / \mathrm{hr}, 6 \mathrm{hrs}$ ) were also performed. Results. The plasma protein binding of FLV was around $83 \%$ and $95 \%$ in control and HL rats, respectively, whereas the FLV recoveries in triglyceride-rich lipoprotein fractions were increased in HL. Therefore, the elevation of lipoproteins was likely responsible for the increase in protein binding in HL. After intravenous administration, the area under the plasma concentration vs. time curve (AUC) in HL was 3.9-fold greater than that in control rats, whereas the distribution ratio of FLV plasma concentration to the brain at a steady state was decreased to approximately $20 \%$ of that of the control. Conclusions. FLV has an affinity to plasma lipoproteins, and their elevation might decrease the FLV biodistribution to brain; the plasma lipoprotein levels could not be found to correlate positively with the FLV pharmacokinetic effect in brain, but rather may attenuate it.
\end{abstract}

This article is open to POST-PUBLICATION REVIEW. Registered readers (see "For Readers") may comment by clicking on ABSTRACT on the issue's contents page.

\section{INTRODUCTION}

Fluvoxamine (FLV) is classified as a selective serotonin reuptake inhibitor (SSRI) and is widely used for the treatment of depression (1-3) and various anxiety disorders such as obsessive-compulsive disorder (OCD) and social anxiety disorder (SAD) (4-7). With characteristic binding to 5-hydroxytryptamine receptor, FLV has less effect on noradrenaline or dopamine receptor, resulting in a different side-effect profile compared with older tricyclic antidepressants and monoamine oxidase inhibitors: lower incidences of anticholinergic and cardioarrhythmic side effects (8-10). Owing to this advantage in safety and tolerability over other antidepressants, FLV is a first-line drug for treatment in elderly patients and subjects with cardiovascular diseases.

Despite clinical outcomes, limited and conflicting information is available on the pharmacodynamics and pharmacokinetics of antidepressants including FLV. For example, it has been unclear why treatment with antidepressants takes approximately 2 to 4 weeks to improve emotional symptoms $(11,12)$. Therapeutic drug monitoring for tricyclic antidepressants has shown their usefulness for therapeutic management of depression (13) and the plasma concentration of FLV has also been shown to reflect its pharmacodynamic effect in several studies $(14,15)$. However, other reports showed large individual variability in FLV plasma concentration, which had no correlation with dosage and clinical response (16-18). Therefore, no optimal plasma concentration range of FLV has yet been identified and factors affecting its plasma levels have also remained unknown.

Corresponding Author: Keizo Fukushima, Department of Clinical Pharmacokinetics, Faculty of Pharmaceutical Sciences, Kobe Gakuin University, 1-1-3 Minatojima, Chuo-ku, Kobe, Japan. E-mail address: keizo@pharm.kobegakuin.ac.jp 
Clozapine, an atypical antidepressant, has been investigated and discussed in several studies focused on the positive relationship between its efficacy and plasma triglyceride levels; many clinical reports and trials have suggested that the elevation of plasma triglyceride levels is positively associated with an improvement in schizophrenia symptoms $(19,20)$. In addition, it was reported that an increase in plasma triglyceride levels alters the distribution pattern of clozapine to plasma lipoprotein contents, probably resulting in the alteration of pharmacological activity of clozapine in hypertriglyceridemia (21). However, few studies have explored the detailed mechanism underlying this relationship and further studies are needed (22).

FLV has moderate lipophilic and protein-binding characteristics (1-octanol/water partition coefficient, 18 , at $\mathrm{pH} 7$; protein binding ratio, approximately $81 \%$ in humans) (23); as well as clozapine, FLV should have certain affinity to plasma lipoproteins. Recent reports suggested that antidepressant treatment with SSRIs is associated with metabolic abnormalities including hyperlipidemia $(24,25)$. In addition, as described above, FLV is frequently prescribed for a specific population, namely, elderly patients and subjects with cardiovascular diseases, who are often also afflicted with primary hyperlipidemia. Thus, there may be a concern over whether the safety and efficacy of FLV are affected under hyperlipidemic (HL) conditions. Nevertheless, the pharmacokinetics of FLV in hyperlipidemia has yet to be investigated.

The aim of the present study was to investigate the pharmacokinetics of FLV in an experimental HL rat model, focusing especially on the affinities of FLV to plasma lipoproteins and their effects on the biodistribution of FLV.

\section{MATERIALS AND METHODS}

\section{Materials}

Fluvoxamine (FLV) was purchased from Wako Pure Chemical Industries (Osaka, Japan). Pluronic F-127 $7^{\circledR}$ (also known as Poloxamer 407, P-407) was obtained from Sigma (St. Louis, MO, USA). Nelfinavir (NFV, internal standard) was extracted from a commercial product, Viracept ${ }^{\circledR}$, and the crude extract was purified by a preparative HPLC method (26). Potassium bromide ( $\mathrm{KBr})$, potassium chloride $(\mathrm{KCl})$ and glucose $(\mathrm{Glu})$ were purchased from Wako Pure Chemical Industries Limited (Osaka, Japan). Sodium pentobarbital was purchased from Nacalai Tesque Incorporated (Kyoto, Japan). Methanol, acetonitrile and all other reagents were of analytical grade and were used without further purification.

\section{Animal Preparation}

All animal experiments were performed in accordance with the Guidelines for Animal Experimentation of Kyoto Pharmaceutical University and Kobe Gakuin University. Male Wistar rats of 12 weeks old (weighing 328-384 g) were obtained from Nippon SLC Co. Ltd. (Hamamatsu, Japan). Rats had free access to food and water, and were maintained in a temperature-controlled facility with a $12 \mathrm{hr}$ light/dark cycle for at least 5 days before use. HL rats were prepared by intraperitoneal administration of P-407 solution $(0.1 \mathrm{~g} / \mathrm{mL}$ in saline $)$ at a dose of $1.0 \mathrm{~g} / \mathrm{kg}$, namely, $10 \mathrm{~mL} / \mathrm{kg}$. Control rats also received the same volume of vehicle without P-407 $(10 \mathrm{~mL} / \mathrm{kg}$ saline). Pharmacokinetic studies of FLV in both HL and control rats were performed at $36 \mathrm{hr}$ after P-407 administration. The whole blood samples of HL and control rats obtained at $36 \mathrm{hr}$ after P-407 administration were also used for in vitro study.

\section{In Vitro Protein Binding and Blood-Plasma Ratio (B-P ratio) Studies}

The erythrocyte vs. buffer or plasma partitioning method (27) was used to determine the protein binding ratio of FLV in rat plasma. Briefly, whole blood samples were taken from cardiac puncture of anesthetized HL and control rats, and then transferred into centrifuge tubes. The blood was divided equally into two tubes. Plasma fraction was obtained by centrifugation of whole blood at 2,500 $\boldsymbol{g}$ for $10 \mathrm{~min}$ at $25^{\circ} \mathrm{C}$. After removal of the plasma fraction and buffy-coat layers, blood cells were washed away carefully from residual plasma with an equal volume of phosphate-buffered saline containing $25 \mathrm{mM}$ glucose (PBS-Glu, $\mathrm{pH}$ 7.4), and subsequently centrifuged at $2,500 \mathrm{~g}$ for $10 \mathrm{~min}$ at $25^{\circ} \mathrm{C}$. This washing procedure was repeated three times. After the third wash, the volume of total erythrocytes was noted in each tube, and either PBS-Glu or plasma diluted 10-fold by PBS-Glu was added to make a hematocrit (HCT) of 0.3. These erythrocyte-buffer or -diluted plasma suspensions were spiked with FLV solutions in methanol to yield final concentrations of $0.1,0.5$, 1.0 and $5.0 \mu \mathrm{g} / \mathrm{mL}$ for both control and HL rats 
( $n=6$ each), where the total methanol concentration was $0.4 \%$. Erythrocyte-buffer and -diluted plasma samples were incubated for $1 \mathrm{hr}$ at $37^{\circ} \mathrm{C}$. After centrifugation at $9,000 \boldsymbol{g}$ for $10 \mathrm{~min}$, the concentration of FLV in the supernatant was determined by LC-MS. The erythrocyte concentration of FLV in the erythrocyte-diluted plasma sample $\left(C_{E}\right)$ was determined by the following equation:

$$
C_{E}=\frac{C_{B}-C_{P} \cdot(1-H C T)}{H C T},
$$

where $C_{B}$ and $C_{P}$ are the total concentration of FLV in the erythrocyte-diluted plasma sample and the plasma concentration, respectively. The partition coefficient for erythrocyte-diluted plasma $\left(P_{P}\right)$ is represented by $C_{E} / C_{P}$.

Likewise, to estimate the erythrocyte concentration of FLV in erythrocyte-buffer sample $\left(C_{E}{ }^{*}\right)$, the total concentrations of FLV in erythrocyte-buffer sample $\left(\mathrm{C}_{\mathrm{B}^{*}}\right)$ and the concentration of FLV in buffer $\left(C_{\text {buffer }}\right)$ were substituted for $C_{B}$ and $C_{P}$ in the above equation, respectively. The partition coefficient for erythrocyte-buffer $\left(P_{b}\right)$ is represented by $C_{E}{ }^{*} / C_{\text {buffer }}$. The $f_{\mathrm{u}}$ values were determined by

$$
\begin{gathered}
f u^{\prime}=\frac{P_{P}}{P_{b}} \\
f u(\%)=100 \times \frac{d \cdot f u^{\prime}}{1-f u^{\prime} \cdot(1-d)},
\end{gathered}
$$

where $f_{\mathrm{u}}^{\prime}$ is the free fraction in dilution plasma and $\boldsymbol{d}$ is the dilution factor (e.g., $\boldsymbol{d}=0.1$ for a 10 -fold dilution of plasma). On the other hand, the B-P ratio was determined by the following method. Drug-free whole blood samples obtained from both HL and control rats $(n=6)$ were spiked with FLV methanol solutions to yield final concentrations 0.1 , $0.5,1.0$ and $5.0 \mu \mathrm{g} / \mathrm{mL}$. After incubation at $37^{\circ} \mathrm{C}$ for $1 \mathrm{hr}$, an aliquot of spiked blood sample was used for the determination of FLV concentration in the whole blood. The remaining blood was centrifuged at $2500 \mathrm{~g}$ for $10 \mathrm{~min}$ at $25^{\circ} \mathrm{C}$ to obtain the plasma fraction, and then FLV concentration in plasma was also measured. The B-P ratio was calculated by dividing the whole blood concentration by the plasma concentration.

\section{In Vitro Distribution of FLV in Plasma Lipoproteins}

Drug-free plasma samples of HL and control rats $(n=6)$ were spiked with FLV methanol solutions to yield a final concentration of $5.0 \mu \mathrm{g} / \mathrm{mL}$. After vortexing and incubation at $37^{\circ} \mathrm{C}$ for $1 \mathrm{hr}$, plasma lipoprotein fractions were obtained on the basis of their hydrated density with a single-step procedure using ultracentrifugation on a potassium bromide $(\mathrm{KBr})$ gradient, as previously reported by Terpstra et al (28). Each lipoprotein fraction was isolated by its density range of $<0.95 \mathrm{~g} / \mathrm{mL}, 0.95-1.006 \mathrm{~g} / \mathrm{mL}$, $1.006-1.063 \mathrm{~g} / \mathrm{mL}, 1.063-1.210 \mathrm{~g} / \mathrm{mL}$ and $>1.210$ $\mathrm{g} / \mathrm{mL}$ for chylomicron (CM), VLDL, LDL, HDL and lipoprotein-deficient fractions (LPDF), respectively. Each obtained fraction was frozen at $-80^{\circ} \mathrm{C}$ until analysis of FLV. The distribution of FLV in lipoprotein fractions and LPDF is represented by the percentage recovered from each fraction.

\section{Pharmacokinetic Study of FLV in Rats}

HL and control rats $(n=5)$ were fasted overnight prior to the intravenous administration of FLV with free access to water. FLV dosing solution was prepared by dissolving in $5.0 \mathrm{mg} / \mathrm{mL}$ saline. Under anesthesia induced by intraperitoneal injection of $50 \mathrm{mg} / \mathrm{kg}$ sodium pentobarbital, rats were placed in a supine position on a heating pad under a surgical lamp to maintain body temperature during the experiment, and a small incision was made in the right neck to expose the external right jugular vein. Subsequently, the bolus intravenous injection of FLV via the external right jugular vein was performed at a dosage of $5.0 \mathrm{mg} / \mathrm{kg}$. Blood samples $(0.25 \mathrm{~mL})$ were taken from the external left jugular vein at 5, 15 and $30 \mathrm{~min}$ and 1, 1.5, 2, 3, 4 and $6 \mathrm{hr}$ after FLV administration and were collected into heparinized centrifuge tubes. Plasma samples were obtained by centrifuging the blood samples at 9000 $\boldsymbol{g}$ for $10 \mathrm{~min}$, and immediately frozen at $-80^{\circ} \mathrm{C}$ until analysis by LC-MS.

\section{Tissue Distributions of FLV for Rat Brain and Liver at Steady State}

The femoral vein of control and HL rats $(n=5)$ was catheterized with polyethylene tubes $(0.58 \mathrm{~mm}$ i.d., $0.98 \mathrm{~mm}$ o.d., SV-45, Natsume Seisakusho, Tokyo, Japan). The dosing solutions of FLV were prepared individually on the basis of the appropriate dosage calculated from the body weight of rats so that they 
received the same volume of the dosing solution; the required amount of FLV $(12 \mathrm{mg} / \mathrm{kg})$ was dissolved in $4 \mathrm{~mL}$ of saline $(3.0 \mathrm{mg} / \mathrm{kg} / \mathrm{mL})$ and was infused into the femoral vein via polyethylene tubes under pentobarbital anesthesia (intraperitoneal injection of $50 \mathrm{mg} / \mathrm{kg}$ ) at a dosing rate of $1.5 \mathrm{mg} / \mathrm{kg} / \mathrm{hr}$ (viz., flow rate of $0.5 \mathrm{~mL} / \mathrm{hr}$ ), starting with a bolus loading dose of $2.5 \mathrm{mg} / \mathrm{kg}$ (dissolved in $0.3 \mathrm{~mL}$ saline) administered into the external left jugular vein to reach the steady state quickly. Blood samples from the external right jugular vein $(250 \mu \mathrm{L})$ were withdrawn into the heparinized microcentrifuge tubes at $0.5,1,1.5,2$, $3,4,5$ and $6 \mathrm{hr}$ after the start of infusion. The blood samples were centrifuged at $9,000 \mathrm{~g}$ for $10 \mathrm{~min}$ to collect plasma samples. After $6 \mathrm{hr}$ of infusion, all rats were sacrificed under anesthesia and immediately perfused with ice-cold $1.15 \%$ potassium chloride to remove blood. Subsequently, the brain and liver were quickly harvested and their wet weights were measured. Then, to the isolated brain and liver were added 9- and 3-fold volumes of phosphate-buffered saline, respectively, with subsequent homogenization using a glass homogenizer. After the removal of cell debris by centrifugation at $1000 \mathrm{~g}$ for $5 \mathrm{~min}$, the obtained supernatant fractions were stored at $-80^{\circ} \mathrm{C}$ until analysis of FLV. The distribution ratios for the brain and liver $\left(\mathrm{D}_{\text {brain }}, \mathrm{D}_{\text {liver }}\right)$ were obtained by dividing the amounts of FLV recovered from the brain and liver $\left(\mathrm{X}_{\text {brain }}, \mathrm{X}_{\text {livber }}\right)$ by the plasma concentration of FLV at a steady state $\left(\mathrm{C}_{\mathrm{ss}}\right)$, respectively, where $\mathrm{C}_{\mathrm{ss}}$ was calculated as the mean of three plasma concentrations at 4,5 and $6 \mathrm{hr}$ after infusion. Likewise, the distribution ratios of unbound FLV for the brain and liver $\left(D_{\text {brain,u }}, D_{\text {liver, } u}\right)$ were obtained by the substitution of $\mathrm{C}_{\mathrm{ss}}$ for the unbound plasma concentrations of FLV at a steady state $\left(\mathrm{C}_{\mathrm{ss}, \mathrm{u}}\right)$, which was obtained by in vitro protein binding study as described above.

\section{Assay Procedure}

FLV concentrations in plasma and the other samples were determined by a previously reported method (29) with some modifications. Briefly, 10 $\mu \mathrm{L}$ of nelfinavir (NFV: internal standard, $50 \mu \mathrm{g} / \mathrm{mL}$ in methanol) and $150 \mu \mathrm{L}(300 \mu \mathrm{L}$ for tissue samples) of $2 \% \mathrm{ZnSO}_{4}$ in $50 \%$ methanol solution were added to aliquots of $100 \mu \mathrm{L}$ plasma sample in a $1.5 \mathrm{~mL}$ microcentrifuge tube and vortexed vigorously for $15 \mathrm{~s}$. After centrifugation at $12,000 \mathrm{~g}$ for $10 \mathrm{~min}$, the supernatant was transferred to a new microcentrifuge tube and then $100 \mu \mathrm{L}$ of $0.1 \mathrm{M}$ sodium hydroxide and $1 \mathrm{~mL}$ of diethyl ether were added. Subsequently, the mixture was vigorously vortexed for $30 \mathrm{~s}$ and centrifuged again at $12,000 \mathrm{~g}$ for $10 \mathrm{~min}$. The aqueous phase in the microcentrifuge tube was then frozen in a cold bath at $-10^{\circ} \mathrm{C}$ and the ether phase was transferred to HPLC sample vials. The organic phase was evaporated to dryness at $70^{\circ} \mathrm{C}$ in a hot water bath with air flow. The residues were reconstituted with $100 \mu \mathrm{L}$ of mobile phase and then $30 \mu \mathrm{L}$ was injected into the LC-MS system (Shimadzu, Kyoto, Japan), which consisted of the following components: a SIL-10A system controller, LC-10ADvp pump, SPD-10A UV detector, SIL-10ADvp automatic injector, CTO-10A column oven and an LC-MS-QP8000a mass spectrometer equipped with a CLASS-8000 workstation. The analytical column for the separation of FLV was a Quicksorb ODS (2.1 mm i.d., $150 \mathrm{~mm}, 5 \mu \mathrm{m}$ size, Chemco, Osaka, Japan), and column temperature was maintained at $60^{\circ} \mathrm{C}$ for all separations. Elution was carried out isocratically at a flow rate of 0.2 $\mathrm{mL} / \mathrm{min}$ with $90 \%$ methanol containing $1 \%$ acetic acid. Mass spectrometry was performed utilizing atmospheric pressure chemical ionization (APCI) in the positive mode. The voltages of the APCI probe and the curved desolvation line (CDL) were set at $5.5 \mathrm{kV}$ and $-30 \mathrm{~V}$, respectively, and the flow rate of the nebulizing gas $\left(\mathrm{N}_{2}\right)$ was set at $2.5 \mathrm{~L} / \mathrm{min}$. The temperatures of the APCI probe and CDL were set at $400^{\circ} \mathrm{C}$ and $250^{\circ} \mathrm{C}$, respectively. The voltage of deflectors was set at $-65 \mathrm{~V}$. The peaks of FLV and NFV were detected as deprotonated ions at 319.2 and $568.0 \mathrm{~m} / \mathrm{z}$, respectively. FLV was quantified by calculating the peak area ratio of FLV against NFV. The standard curves $(5.0-0.005 \mu \mathrm{g} / \mathrm{mL})$ were prepared in corresponding drug-free matrixes: plasma, whole blood, lipoprotein fractions and tissue homogenates. The lower limits of quantification (LLOQ; signal to noise ratio of 10:1) in each matrix were less than $0.01 \mu \mathrm{g} / \mathrm{mL}$ for plasma and lipoprotein fractions, and $0.05 \mu \mathrm{g} / \mathrm{mL}$ for whole blood and tissue homogenates. The standard curves in each matrix were linear over the range of concentration $(r>0.996)$.

\section{Pharmacokinetic Analysis}

Noncompartmental pharmacokinetic analysis was applied to the plasma concentration-time profile of FLV using a computer program, WinNonlin ${ }^{\mathbb{B}}$ (Pharsight, Mountain View, CA). The terminal elimination rate constant $\left(\lambda_{z}\right)$ was obtained by the linear regression of at least three data points from 
the terminal portion of the plasma concentration-time profile. The terminal elimination half-life $\left(t_{1 / 2}\right)$ was determined by dividing $\ln 2$ by $\lambda_{z}$. The area under the plasma concentration-time curve from 0 to the last measured point $\left(\mathrm{AUC}_{0 \text {-last }}\right)$ was calculated using the linear trapezoidal rule up to the last measured plasma concentration $\left(\mathrm{C}_{\mathrm{p}(\text { last })}\right)$, and the area under the plasma concentration-time curve from 0 to infinity $\left(\mathrm{AUC}_{0-\infty}\right)$ was extrapolated to infinity using a correction term, namely, $\mathrm{C}_{\mathrm{p}(\text { last })} / \lambda_{\mathrm{z}}$. The area under the first-moment curve from 0 to infinity (AUMC) was also calculated using the linear trapezoidal rule and the addition of the correction term after the last measured point $\left(\mathrm{t}_{\text {last }}\right)$ to infinity, namely, $\mathrm{t}_{\text {last }} * \mathrm{C}_{\mathrm{p}(\text { last })} / \lambda_{\mathrm{z}}+\mathrm{C}_{\mathrm{p}(\text { last })} /\left(\lambda_{\mathrm{z}}\right)^{2}$. The mean residence time (MRT) was calculated by dividing AUMC by $\mathrm{AUC}_{0-\infty}$. Total body plasma clearance $\left(\mathrm{CL}_{\text {tot }}\right)$ was calculated by $D / \mathrm{AUC}_{0-\infty}$, where $D$ represents the dose administered. Blood clearance $\left(\mathrm{CL}_{\text {blood }}\right)$ was estimated by dividing $\mathrm{CL}_{\text {tot }}$ by the B-P ratio. The volume of distribution at a steady state $\left(\mathrm{Vd}_{\mathrm{ss}}\right)$ was calculated by multiplying $\mathrm{CL}_{\text {tot }}$ by MRT.

\section{STATISTICAL ANALYSIS}

All values are expressed as the mean \pm S.E. Statistical analysis in the protein binding and B-P ratio studies was performed by one-way ANOVA or Student's unpaired $t$-test. In other experiments, statistical differences of the means were assumed to be significant when $p<0.05$ by Student's unpaired $t$-test.

\section{RESULTS}

The results from in vitro protein binding and B-P ratio studies are summarized in Table 1 . In this study, the protein binding analysis of FLV was performed by the erythrocyte vs. buffer or plasma partitioning method (27). The authors investigated the protein binding ratio of variable drugs and the precision of this method, and reported that, in the case of highly protein-bound drugs, it depends not only on the true $f_{\mathrm{u}}$ value but also on the $P_{P}$ value; therefore. It was recommended that for such drugs protein binding ratios should be determined in diluted plasma, where $f_{\mathrm{u}}^{\prime}$ is increased and $P_{P}$ is more than 0.5 . Accordingly, a series of diluted plasma (1-, 2-, 4- and 10-fold) was tested, and the plasma diluted 10-fold $\left(P_{P}>2.1\right.$ in HL) showed better precision (data not shown) and was thus applied to the present study. In the concentration range of 0.1 to $5.0 \mu \mathrm{g} / \mathrm{mL}$, the plasma protein bindings of FLV were very consistent within control rats $\left(83.6-84.7 \% ; f_{u}=15.3-16.4 \%\right)$ and HL rats $\left(93.7-96.1 \% ; f_{u}=3.9-6.3 \%\right)$, with values in $\mathrm{HL}$ rats being significantly higher. Likewise, the B-P ratios also appeared to be consistent within each group of model rats (2.15-2.49 in control; 1.12-1.27 in HL rats), but those in HL rats were significantly lower than those in control rats.

Figure 1 shows the distribution patterns of FLV in plasma lipoproteins of control and HL rats. In comparison to control rats, the recovery percentages of FLV were significantly increased in CM, VLDL and LDL fractions: 7.87 to $29.65 \%$ in $\mathrm{CM}, 4.03$ to $17.94 \%$ in VLDL and 5.15 to 17.04 in LDL. In contrast, the recovery percentages of FLV from HDL and LPDF were decreased in HL rats: 8.77 to $3.96 \%$ in HDL and 61.30 to $26.46 \%$ in LPDF.

Figure 2 shows the plasma concentration vs. time curves after $5.0 \mathrm{mg} / \mathrm{kg}$ FLV intravenous administration to control and HL rats, and the obtained pharmacokinetic parameters are summarized in Table 2. After intravenous administration, plasma concentrations of FLV in HL rats were consistently higher than those in control rats and the areas under the plasma concentration vs time curve (AUC) in HL rats were increased by 3.94-fold compared with controls. There were no significant differences in terminal half-life $\left(\mathrm{t}_{1 / 2}\right)$ or mean residence time (MRT) between control and HL rats, whereas total body plasma clearance $\left(\mathrm{CL}_{\mathrm{tot}}\right)$, blood clearance $\left(\mathrm{CL}_{\text {blood }}\right)$ and distribution volume at a steady state $\left(\mathrm{Vd}_{\mathrm{ss}}\right)$ were decreased in $\mathrm{HL}$ rats.

Table 3 shows the tissue distributions of FLV to rat brain and liver at a steady state in control and HL rats. The plasma concentration of FLV at a steady state $\left(\mathrm{C}_{\mathrm{ss}}\right)$ in control rats was significantly lower than that in HL rats. However, the estimated unbound plasma concentration of FLV at a steady state $\left(\mathrm{C}_{\mathrm{ss}, \mathrm{u}}\right)$ in control, which was calculated using in vitro protein binding, was higher than that in $\mathrm{HL}$ rats. The amount of FLV recovered from the brain $\left(\mathrm{X}_{\text {brain }}\right)$ in HL rats was less than half of that in control rats. The distribution ratios of total and unbound FLV plasma concentration to the brain ( $D_{\text {brain }}$ and $D_{\text {brain,u }}$ ) were also significantly decreased in HL rats. In contrast, the amount of FLV recovered from the liver $\left(\mathrm{X}_{\text {liver }}\right)$ in $\mathrm{HL}$ was 3.4-fold higher than that in control rats. In addition, the distribution ratios of total and unbound FLV plasma concentration to the liver $\left(\mathrm{D}_{\text {liver }}\right.$ and $\left.\mathrm{D}_{\text {liver, } \mathrm{u}}\right)$ were increased in HL rats. 


\begin{tabular}{|c|c|c|c|c|}
\hline \multirow{2}{*}{$\begin{array}{l}\text { FLV concentration } \\
(\mu \mathrm{g} / \mathrm{mL})\end{array}$} & \multicolumn{2}{|c|}{ Plasma protein binding ratio $(\%)$} & \multicolumn{2}{|c|}{ Blood-plasma concentration ratio ${ }^{a}$} \\
\hline & Control & $\mathrm{HL}$ & Control & $\mathrm{HL}$ \\
\hline 0.1 & $83.6 \pm 1.1$ & $93.7 \pm 1.0^{*}$ & $2.49 \pm 0.11$ & $1.27 \pm 0.07^{*}$ \\
\hline 0.5 & $83.9 \pm 0.3$ & $94.7 \pm 0.8^{*}$ & $2.19 \pm 0.07$ & $1.12 \pm 0.04^{*}$ \\
\hline 1.0 & $83.9 \pm 0.9$ & $96.1 \pm 0.5^{*}$ & $2.15 \pm 0.07$ & $1.15 \pm 0.05^{*}$ \\
\hline 5.0 & $84.7 \pm 1.0$ & $95.5 \pm 0.8^{*}$ & $2.30 \pm 0.05$ & $1.20 \pm 0.06^{*}$ \\
\hline
\end{tabular}

${ }^{a}$ Blood-plasma concentration ratios were obtained by $\mathrm{C}_{\text {blood }} / \mathrm{C}_{\text {plasma. }}$.

${ }^{*} p<0.01$, significantly different from the control by Student's unpaired $t$-test.

Each value represents the mean \pm S.E. of 6 rats.

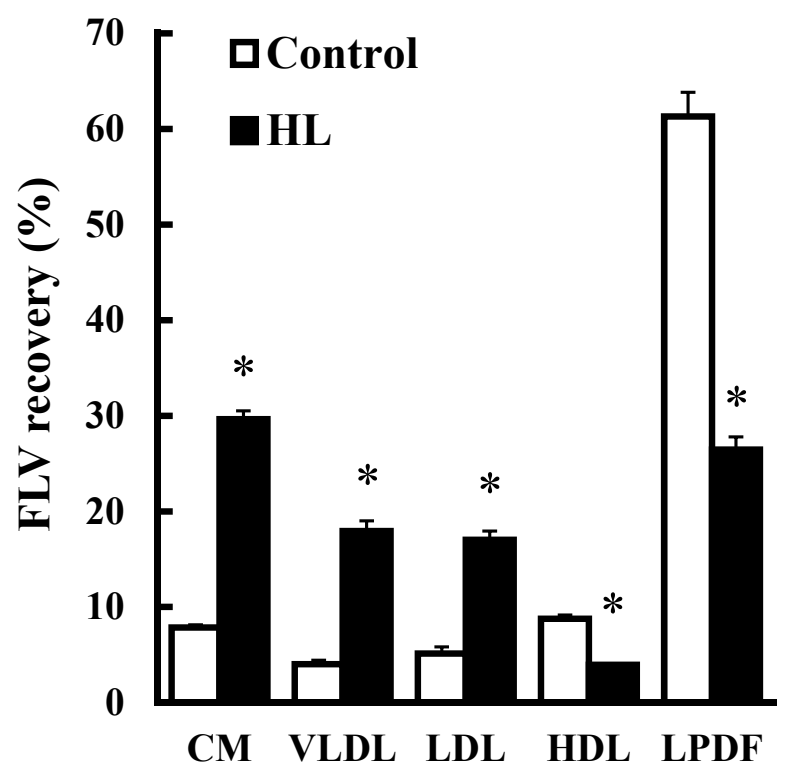

Figure 1. In vitro distribution of FLV in rat plasma lipoproteins. Plasma from HL and control rats was spiked with FLV $(5.0 \mu \mathrm{g} / \mathrm{mL})$. Blood used in this study was collected at 36 hours after P407 $(1 \mathrm{~g} / \mathrm{kg})$ intraperitoneal administration (HL rats) or that of the same volume of vehicle without P-407 (control). Open bar, control rats; closed bar, HL rats. CM, chylomicron; VLDL, very low density lipoprotein; LDL, low density lipoprotein; HDL, high density lipoprotein; LPDF, lipoprotein-deficient fractions. Each bar shows the means \pm S.E. of 6 experiments, ${ }^{*} \mathrm{p}<0.01$ statistically significant difference versus control.

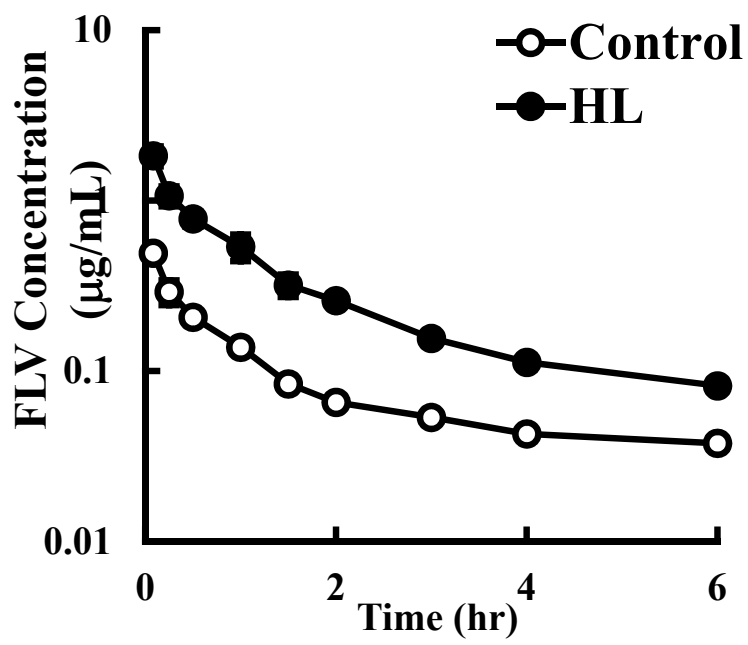

Figure 2. The mean plasma concentration profiles of FLV after intravenous administration to control rats (open circle) and $\mathrm{HL}$ rats (closed circle) at a dosage of $5.0 \mathrm{mg} / \mathrm{kg}$. Experiments were performed at $36 \mathrm{~h}$ after $\mathrm{P}-407$ (1 g/kg) intraperitoneal administration (HL rats) or that of the same volume of vehicle without P-407 (control). Each symbol with a bar represents the mean \pm S.E. of 5 rats. 


\begin{tabular}{lcc}
\hline \multicolumn{2}{c}{ Table 2. Pharmacokinetic parameters of FLV after its intravenous administration, at $5 \mathrm{mg} / \mathrm{kg}$, to control and HL rats. } \\
\hline \multicolumn{1}{c}{ Pharmacokinetic parameters } & Control & HL \\
\hline $\mathrm{t}_{1 / 2}(\mathrm{hr})$ & $2.91 \pm 0.15$ & $2.90 \pm 0.09$ \\
$\mathrm{MRT}(\mathrm{hr})$ & $3.17 \pm 0.17$ & $2.81 \pm 0.21$ \\
$\mathrm{CL}_{\text {tot }}(\mathrm{L} / \mathrm{hr} / \mathrm{kg})$ & $7.94^{ \pm} 0.39$ & $2.33 \pm 0.15^{*}$ \\
$\mathrm{CL}_{\text {blood }}(\mathrm{L} / \mathrm{hr} / \mathrm{kg})^{\mathrm{a}}$ & $3.20^{ \pm} 0.16$ & $2.01 \pm 0.13^{*}$ \\
$\mathrm{Vd}_{\mathrm{ss}}(\mathrm{L} / \mathrm{kg})$ & $25.19^{ \pm} 1.92$ & $6.66^{ \pm} 0.86^{*}$ \\
$\mathrm{AUC}_{0-\infty}(\mu \mathrm{g} / \mathrm{mL} \cdot \mathrm{hr})$ & $0.471 \pm 0.029$ & $1.856^{ \pm} 0.149^{*}$ \\
\hline
\end{tabular}

${ }^{\mathrm{a}} \mathrm{CL}_{\text {blood: }}$ blood clearances, which were calculated using the in vitro blood-plasma concentration ratios at $0.1 \mu \mathrm{g} / \mathrm{mL}$ in control (2.49) and $0.5 \mu \mathrm{g} / \mathrm{mL}$ in $\mathrm{HL}$ rats (1.12).

${ }^{*} p<0.01$, significantly different from the control by Student's unpaired $t$-test.

Each value represents the mean \pm S.E. of 5 rats.

Table 3. Plasma concentrations and distribution ratios to brain and liver at a steady state by continuous infusion of FLV, at $1.5 \mathrm{mg} / \mathrm{hr} / \mathrm{kg}$, to control and HL rats.

\begin{tabular}{lcc}
\hline & Control & HL \\
\hline Plasma & & \\
$\mathrm{C}_{\mathrm{ss}}(\mu \mathrm{g} / \mathrm{mL})$ & $0.186 \pm 0.012$ & $0.427 \pm 0.025^{* *}$ \\
$\mathrm{C}_{\mathrm{ss}, \mathrm{u}}(\mu \mathrm{g} / \mathrm{mL})$ & $0.0306 \pm 0.0023$ & $0.0225 \pm 0.0013^{*}$ \\
Brain & & \\
$\mathrm{X}_{\text {brain }}(\mu \mathrm{g} / \mathrm{g}$, tissue $)$ & $0.84 \pm 0.02$ & $0.39 \pm 0.04^{* *}$ \\
$\mathrm{D}_{\text {brain }}$ & $4.51 \pm 0.13$ & $0.92 \pm 0.10^{* *}$ \\
$\mathrm{D}_{\text {brain,u }}$ & $27.5 \pm 0.8$ & $17.5 \pm 1.9^{* *}$ \\
Liver & & \\
$\mathrm{X}_{\text {liver }}(\mu \mathrm{g} / \mathrm{g}$, tissue $)$ & $1.20 \pm 0.11$ & $4.08 \pm 0.18^{* *}$ \\
$\mathrm{D}_{\text {liver }}$ & $6.43 \pm 0.61$ & $9.54 \pm 0.42^{* *}$ \\
$\mathrm{D}_{\text {liver,u }}$ & $39.2 \pm 3.7$ & $180.9 \pm 7.9^{* *}$ \\
\hline $\mathrm{C}_{\text {s. }}$ & & \\
\hline
\end{tabular}

$\mathrm{C}_{\mathrm{ss}}$ : plasma concentrations of FLV at a steady state.

$\mathrm{C}_{\mathrm{ss}, \mathrm{u}}$ : unbound plasma concentrations of FLV at a steady state, which were calculated using the in vitro protein binding ratios at $0.1 \mu \mathrm{g} / \mathrm{mL}$ in control $(83.6 \%)$ and $0.5 \mu \mathrm{g} / \mathrm{mL}$ in $\mathrm{HL}$ rats $(94.7 \%)$.

$\mathrm{X}_{\text {brain or liver: }}$ amounts of FLV recovered from the brain or liver.

$\mathrm{D}_{\text {brain or liver: }}$ distribution ratios of FLV plasma concentration to the brain or liver, which were determined by

$\mathrm{X}_{\text {brain or liver }} / \mathrm{C}_{\mathrm{ss}}$.

$\mathrm{D}_{\text {brain,u or liver,u }}$ : distribution ratios of unbound FLV plasma concentration to the brain or liver, which were determined by $\mathrm{X}_{\text {brain or liver }} / \mathrm{C}_{\mathrm{ss}, \mathrm{u}}$.

${ }^{* *} p<0.01 ;{ }^{*} p<0.05$, significantly different from the control by Student's unpaired $t$-test.

Each value represents the mean \pm S.E. of 5 rats.

\section{DISCUSSION}

In the present study, in vitro and in vivo experiments were performed using experimental HL rats to investigate the relationship between plasma lipoproteins and FLV pharmacokinetics. We previously reported that cholesterol and triglyceride levels in this rat model were approximately 9.6 and 29.9 times higher than those in control rats, respectively (30). In vitro protein binding study showed almost consistent values in control rats in the tested range (around 84\%), which is relatively 
close to that in human $(81 \%)$. In contrast, protein binding in HL was significantly higher than that in control; free concentrations of FLV in HL were decreased to $24-38 \%$ that of control. Protein binding studies in control and $\mathrm{HL}$ rats were investigated in the concentration range of 0.1-5.0 $\mu \mathrm{g} / \mathrm{mL}$, which was frequently observed after intravenous administration to control and HL (5.0 $\mathrm{mg} / \mathrm{kg}$ ). The protein binding at lower than 0.05 $\mu \mathrm{g} / \mathrm{mL}$ could not be determined because of the lower limit of quantification $(0.01 \mu \mathrm{g} / \mathrm{mL}) ; C_{\text {buffer }}$ in $0.05 \mu \mathrm{g} / \mathrm{mL}$ spiked sample was less than 0.005 $\mu \mathrm{g} / \mathrm{mL}$. In the tested range, protein binding in control rats showed almost consistent values (around $84 \%$ ), which is relatively close to that in human $(81 \%)$; therefore, it was considered to be linear in this range; likewise, there was no significant difference in protein binding in HL, and it was also considered to be linear. However, protein binding in HL was significantly higher than that in control at the corresponding concentration; free concentrations of FLV in HL were decreased to $24-38 \%$ that of the control. The B-P ratios of FLV in control rats were ranged from 2.49 to 2.15 , where there was no statistical difference between tested concentrations and it was considered to be linear. Compared with other antipsychotic agents, FLV showed high-affinity binding of erythrocytes; fluoxetine, 0.83 (31); risperidone, 0.85 (32); chlorpromazine, 1.48 (33); imipramin, 1.67 (34). However, the B-P ratios of FLV in HL were decreased to $51-53 \%$ that of the control (Table 1). Considering the increases of FLV recoveries in lipoprotein fractions (CM, VLDL and LDL) and their decrease in the LPDF fraction in HL (Figure 1), FLV must have an affinity to plasma lipoproteins; therefore, the increase in plasma lipoproteins in HL could be responsible for the increase of plasma protein binding and the decrease of B-P ratio.

It has been reported that FLV is mainly metabolized by hepatic cytochrome P450 2D6 (35) and eleven metabolites are identified in human; the main route of metabolism of FLV begins with oxidative elimination of the methoxyl group, another route with removal of the primary amino group and none of the metabolites is likely to possess psychotropic activity (36). Accordingly, only the parent FLV was investigated in the present study.

After intravenous administration, AUC was significantly increased and $\mathrm{CL}_{\text {tot }}, \mathrm{CL}_{\text {blood }}$ and $\mathrm{Vd}_{\mathrm{ss}}$ were decreased in HL rats, whereas $t_{1 / 2}$ was not altered (Figure 2 and Table 2). Many studies have investigated the effect of drug-lipid complex on its metabolism; it has been reported that some lipophilic drugs that have high affinity to plasma lipoproteins often form drug-lipid complexes and their selective uptake is facilitated via lipoprotein receptors into tissues, such as in liver and kidney, resulting in the maintenance or enhancement of the pharmacodynamic effect, metabolism or toxicity despite the increase in protein binding (30,37-40). In the present study, although the calculated unbound plasma concentration of FLV at a steady state $\left(\mathrm{C}_{\mathrm{ss}, \mathrm{u}}\right)$ in $\mathrm{HL}$ was significantly lower than that in control, the amounts of FLV recovered from the liver $\left(\mathrm{X}_{\text {liver }}\right)$ and the distribution ratio of FLV plasma concentration to liver $\left(\mathrm{D}_{\text {liver }}\right)$ were significantly increased in HL; moreover, the distribution ratio of unbound FLV plasma concentration to liver $\left(D_{\text {liver,u }}\right)$ was more than 4-fold higher than that in control (Table 3). These results suggest that active transport of FLV to liver, such as by selective uptake of FLV-lipid complex via lipoprotein receptors, could occur, resulting in $t_{1 / 2}$ comparable to that in the control. In contrast, $\mathrm{X}_{\text {brain }}$ and $\mathrm{D}_{\text {brain }}$ were significantly decreased in $\mathrm{HL}$; $\mathrm{D}_{\text {brain,u }}$ was also decreased to $64 \%$ that of control, whereas if the brain distribution of FLV were responsible only for simple diffusion of unbound FLV in plasma, it should be unchanged between the two model rats. It is well known that FLV pharmacokinetics shows nonlinearity in the therapeutic range, and Geldof et al. investigated the pharmacokinetic modeling of FLV and reported that the saturation of P-glycoprotein (Pgp) in the blood-brain barrier (BBB), which mediates active efflux of FLV from brain, should contribute to the nonlinear brain distribution, even when the actually observed concentration is below the concentration at which full saturation occurs (41). As it was reported that P-407-induced hyperlipidemia does not affect physiological conditions except for plasma lipoprotein levels (42), if there is no alteration in the expression and activity of Pgp in BBB under P-407-induced hyperlipidemia, the decrease of $D_{\text {brain,u }}$ in HL might be based on the nonlinear brain distribution characteristics of FLV. It was noted here that $\mathrm{D}_{\text {brain }}$ in $\mathrm{HL}$, which was simply determined by dividing $\mathrm{X}_{\text {brain }}$ by $\mathrm{C}_{\mathrm{ss}}$, was decreased to approximately $20 \%$ that of control; in other words, the brain concentration of FLV in HL must be far lower than that predicted by $D_{\text {brain }}$ in control. Therefore, prediction of the pharmacodynamic effect by FLV plasma concentration in dyslipidemic patients would lead to underestimation. 
The pharmacokinetics of lipophilic compounds such as amiodarone (43), atazanavir (30), cyclosporine A (37), and nifedipine (44), have been investigated in P-407-induced HL and a similar trend was reported whereby increases in plasma concentration and decreases in plasma unbound fractions were observed in the HL state, with simultaneous decreases in clearance and volume of distribution. However, the changes in biodistribution to tissues of a drug could be dependent on its physical property and show a complex pattern, with increases and decreases in selected tissues. Growing evidence has supported the hypothesis that the uptake of a lipophilic drug to some tissues such as liver, kidney, and spleen via lipoprotein receptors might be increased by complex formation of a drug with elevated serum lipids, whereas to other tissues, the uptake was decreased with corresponding decrease in plasma unbound fraction $(39,43,45)$.

The positive relationship between the efficacy of clozapine and plasma triglyceride levels has been reported, but few studies have investigated underlying mechanism. The alteration of brain distribution following the formation of a drug-lipid complex in hypertriglyceridemic condition has been proposed. Gershkovich et al. investigated the brain penetration of clozapine in postprandial hypertriglyceridemic and normolipidemic rats and reported no statistical differences in plasma or brain concentration, resulting in no changes of brain penetration. Therefore, their results did not support the above-mentioned explanation (22). On the other hand, in this study, the brain distribution of FLV ( $\left.D_{\text {brain }}\right)$ was significantly decreased in HL $(20.34 \%$ of control), where FLV showed a high affinity to triglyceride-rich fraction (e.g. CM fractions). Similar to FLV, amiodarone and clomipramine have a high affinity to triglyceride in plasma and it was reported that AUC in brain of amiodarone and the concentration ratio of brain to plasma of clomipramine were dramatically decreased to $6.26 \%$ and $10.96 \%$ those of normolipidemic rats, respectively $(43,46,47)$. It was reported that clozapine has no affinity to $\mathrm{CM}$ in an in-silico model (48). Considering these observations, the distribution pattern to tissues in the HL condition might be related to plasma lipoprotein fractions, whereas there have been conflicting reports about whether drug-lipid complex can penetrate the BBB $(49,50)$.

Several studies investigated the effect of FLV on plasma lipoprotein levels and reported that FLV may reduce serum cholesterol levels $(51,52)$. In contrast, there have been few studies focused on the effect of plasma lipoprotein levels on FLV pharmacological effect. The present study suggests that the elevated plasma lipoproteins increase the protein binding of FLV and reduce the distribution ratio of FLV to brain; they were not found to correlate positively with the FLV pharmacokinetic effect in brain, but rather may attenuate it. However, there were, at least, two limitations in this study: P-407-induced hyperlipidemia did not actually reflect the nature of hyperlipidemia, whereas this model is considered to be useful for the investigation of the direct effect of lipoproteins. Another limitation is that the pharmacokinetic studies were only performed on the disposition of FLV without an absorption process. Therefore, to evaluate the net pharmacokinetic alterations of FLV in hyperlipidemia, further investigation is warranted under clinically relevant conditions.

\section{CONCLUSION}

The elevated plasma lipoprotein levels increased the protein binding of FLV and the recoveries of FLV in triglyceride-rich lipoprotein fractions, probably forming an FLV-lipid complex. Despite the decrease of FLV free concentration, the uptake of FLV in liver was enhanced in HL rats, maintaining the metabolism of FLV. In contrast, the distribution ratio of FLV plasma concentration to brain in HL rats was extremely low ( $20 \%$ of that of control), whereas FLV plasma concentration in HL rats was more than 2-fold higher than that in control. Therefore, the plasma lipoprotein levels were not found to correlate positively with the FLV biodistribution to brain, but rather may attenuate it

\section{ACKNOWLEDGMENT}

This research was supported in part by Grant-in-Aid for Health Science Research of Kobe Gakuin University.

\section{REFERENCES}

1. Wilde MI, Plosker GL, Benfield P. Fluvoxamine. An updated review of its pharmacology, and therapeutic use in depressive illness. Drugs, 1993;46:895-924.

2. Ottevanger EA. The efficacy of fluvoxamine in patients with severe depression. Prog Neuropsychopharmacol Biol Psychiatry, 1994;18:731-740.

3. Claghorn JL, Earl CQ, Walczak DD, Stoner KA, Wong LF, Kanter D, Houser VP. Fluvoxamine 
maleate in the treatment of depression: a single-center, double-blind, placebo-controlled comparison with imipramine in outpatients. J Clin Psychopharmacol, 1996;16:113-120.

4. Mundo E, Rouillon F, Figuera ML, Stigler M. Fluvoxamine in obsessive-compulsive disorder: similar efficacy but superior tolerability in comparison with clomipramine. Hum Psychopharmacol, 2001;16:461-468.

5. Milanfranchi A, Ravagli S, Lensi P, Marazziti D, Cassano GB. A double-blind study of fluvoxamine and clomipramine in the treatment of obsessive-compulsive disorder. Int Clin Psychopharmacol, 1997;12:131-136.

6. Stein MB, Fyer AJ, Davidson JR, Pollack MH, Wiita B. Fluvoxamine treatment of social phobia (social anxiety disorder): a double-blind, placebo-controlled study. Am J Psychiatry, 1999;156:756-760.

7. Asakura S, Tajima O, Koyama T. Fluvoxamine treatment of generalized social anxiety disorder in Japan: a randomized double-blind, placebo-controlled study. Int J Neuropsychopharmacol, 2007;10:263-274.

8. Potter WZ, Rudorfer MV, Manji H. The pharmacologic treatment of depression. N Engl J Med, 1991;325:633-642.

9. Rapaport M, Coccaro E, Sheline Y, Perse T, Holland P, Fabre L, Bradford D. A comparison of fluvoxamine and fluoxetine in the treatment of major depression. J Clin Psychopharmacol, 1996;16:373-378.

10. Wisner KL, Gelenberg AJ, Leonard H, Zarin D, Frank E. Pharmacologic treatment of depression during pregnancy. JAMA, 1999;282:1264-1269.

11. Georgotas A, McCue RE, Cooper TB, Nagachandran N, Friedhoff A. Factors affecting the delay of antidepressant effect in responders to nortriptyline and phenelzine. Psychiatry Res, 1989;28:1-9.

12. Posternak MA, Zimmerman M. Is there a delay in the antidepressant effect? A meta-analysis. J Clin Psychiatry, 2005;66:148-158.

13. Linder MW, Keck PE Jr. Standards of laboratory practice: antidepressant drug monitoring. National Academy of Clinical Biochemistry. Clin Chem, 1998;44:1073-1084.

14. Schwarzenbach F, Netillard C, Demoly P, Bisschop $\mathrm{D}$, Limat S, Bouquet S, Vandel S, Bel AM, Woronoff-Lemsi MC. Antidepressant response and fluvoxamine plasma concentrations: a pilot study. Pharm World Sci, 2003;25:27-29.

15. Takano A, Suhara T, Ichimiya T, Yasuno F, Suzuki K. Time course of in vivo 5-HTT transporter occupancy by fluvoxamine. J Clin Psychopharmacol, 2006;26:188-191.

16. Suzuki Y, Fukui N, Sawamura K, Sugai T, Watanabe J, Ono S, Inoue Y, Ozdemir V, Someya T. Concentration-response relationship for fluvoxamine using remission as an endpoint: a receiver operating characteristics curve analysis in major depression. J Clin Psychopharmacol, 2008;28:325-328.

17. Katoh Y, Uchida S, Kawai M, Takei N, Mori N, Kawakami J, Kagawa Y, Yamada S, Namiki N, Hashimoto H. Onset of clinical effects and plasma concentration of fluvoxamine in Japanese patients. Biol Pharm Bull, 2010;33:1999-2002.

18. Kasper S, Dötsch M, Kick H, Vieira A, Möller HJ. Plasma concentrations of fluvoxamine and maprotiline in major depression: implications on therapeutic efficacy and side effects. Eur Neuropsychopharmacol, 1993;3:13-21.

19. Pande S, Procyshyn RM, Nazerali M, Attwood D, Chow K. Do triglycerides modulate the effectiveness of clozapine? Int Clin Psychopharmacol, 2002;17:197-199.

20. Procyshyn RM, Wasan KM, Thornton AE, Barr AM, Chen EY, Pomarol-Clotet E, Stip E, Williams R, Macewan GW, Birmingham CL, Honer WG; Clozapine and Risperidone Enhancement Study Group. Changes in serum lipids, independent of weight, are associated with changes in symptoms during long-term clozapine treatment. J Psychiatry Neurosci, 2007;32:331-338.

21. Procyshyn RM, Kennedy NB, Marriage S, Wasan KM. Plasma protein and lipoprotein distribution of clozapine. Am J Psychiatry, 2001;158:949-951.

22. Gershkovich P, Sivak O, Sharma A, Barr AM, Procyshyn R, Wasan KM. Effect of hypertriglyceridemia on the pharmacokinetics and blood-brain barrier penetration of clozapine and norclozapine following administration to rats. Eur Neuropsychopharmacol $_{\Re} 2010 ; 20: 545-552$.

23. Fluvoxamine (Luvox ) [Drug Information]. Astellas Pharma Inc, 2011.

24. Raeder MB, Bjelland I, Emil VS, Steen VM. Obesity, dyslipidemia, and diabetes with selective serotonin reuptake inhibitors: the Hordaland Health Study. J Clin Psychiatry, 2006;67:1974-1982.

25. Wei F, Crain AL, Whitebird RR, Godlevsky OV, O'Connor PJ. Effects of paroxetine and sertraline on low-density lipoprotein cholesterol: an observational cohort study. CNS Drugs, 2009;23:857-865.

26. Gao W, Kishida T, Kimura K, Kageyama M, Sumi M, Yoshikawa Y, Shibata N, Takada K. Sensitive and simultaneous determination of HIV protease inhibitors in rat biological samples by liquid chromatography-mass spectrometry. Biomed Chromatogr. 2002;16:267-73.

27. Schuhmacher J, Buhner K, Witt-Laido A. Determination of the free fraction and relative free fraction of drugs strongly bound to plasma proteins. J Pharm Sci, 2000;89:1008-1021.

28. Terapstra AH, Woodward CJ, Sanchez-Muniz FJ. Improved techniques for the separation of serum lipoproteins by density gradient ultracentrifugation: 
visualization by prestaining and rapid separation of serum lipoproteins from small volumes of serum. Anal Biochem, 1981;111:149-157.

29. Katoh Y, Uchida S, Kawai M, Takei N, Mori N, Kawakami J, Kagawa Y, Yamada S, Namiki N, Hashimoto $H$. Effects of cigarette smoking and cytochrome P450 2D6 genotype on fluvoxamine concentration in plasma of Japanese patients. Biol Pharm Bull, 2010;33:285-288.

30. Fukushima K, Shibata M, Mizuhara K, Aoyama H, Uchisako R, Kobuchi S, Sugioka N, Takada K. Effect of serum lipids on the pharmacokinetics of atazanavir in hyperlipidemic rats. Biomed Pharmacother, 2009;63:635-642.

31. Caccia S, Cappi M, Fracasso C, Garattini S. Influence of dose and route of administration on the kinetics of fluoxetine and its metabolite norfluoxetine in the rat. Psychopharmacology. 1990;100:509-14.

32. De Buck SS, Sinha VK, Fenu LA, Nijsen MJ, Mackie CE, Gilissen RA. Prediction of human pharmacokinetics using physiologically based modeling: a retrospective analysis of 26 clinically tested drugs. Drug Metab Dispos. 2007;35:1766-80.

33. Shibata Y, Takahashi H, Ishii Y. A convenient in vitro screening method for predicting in vivo drug metabolic clearance using isolated hepatocytes suspended in serum. Drug Metab Dispos 2000;28: 1518-1523.

34. Lin TH, Sawada Y, Sugiyama Y, Iga T, Hanano M. Effect of phenobarbitone on the distribution and elimination of imipramine in rats. $\mathrm{J}$ Pharm Pharmacol. 1985;37:735-8.

35. Spigset O, Axelsson S, Norström A, Hägg S, Dahlqvist R. The major fluvoxamine metabolite in urine is formed by CYP2D6. Eur J Clin Pharmacol. 2001;57:653-8.

36. Overmars H, Scherpenisse PM, Post LC. Fluvoxamine maleate: metabolism in man. Eur J Drug Metab Pharmacokinet. 1983;8:269-80.

37. Brocks DR, Ala S, Aliabadi HM. The effect of increased lipoprotein levels on the pharmacokinetics of cyclosporine $A$ in the laboratory rat. Biopharm Drug Dispos, 2006;27:7-16.

38. Wasan KM, Rosenblum MG, Cheung L, Lopez-Berestein G. Influence of lipoproteins on renal cytotoxicity and antifungal activity of amphotericin B. Antimicrob Agents Chemother, 1994;38:223-227.

39. Ramaswamy M, Peteherych KD, Kennedy AL, Wasan KM. Amphotericin B lipid complex or amphotericin B multiple-dose administration to rabbits with elevated plasma cholesterol levels: pharmacokinetics in plasma and blood, plasma lipoprotein levels, distribution in tissues, and renal toxicities. Antimicrob Agents Chemother, 2001;45:1184-1191.

40. Sugioka N, Haraya K, Maeda Y, Fukushima K,
Takada K. Pharmacokinetics of human immunodeficiency virus protease inhibitor, nelfinavir, in poloxamer 407-induced hyperlipidemic model rats. Biol Pharm Bull, 2009;32:269-275.

41. Geldof M, Freijer J, van Beijsterveldt L, Danhof M. Pharmacokinetic modeling of non-linear brain distribution of fluvoxamine in the rat. Pharm Res, 2008;25:792-804.

42. Wout ZG, Pec EA, Maggiore JA, Williams RH, Palicharla P, Johnston TP. Poloxamer 407-mediated changes in plasma cholesterol and triglycerides following intraperitoneal injection to rats. J Parenter Sci Technol, 1992;46:192-200.

43. Shayeganpour A, Korashy H, Patel JP, El-Kadi AO, Brocks DR. The impact of experimental hyperlipidemia on the distribution and metabolism of amiodarone in rat. Int J Pharm. 2008;361:78-86.

44. Eliot LA, Foster RT, Jamali F. Effects of hyperlipidemia on the pharmacokinetics of nifedipine in the rat. Pharm Res. 1999;16:309-13.

45. Patel JP, Fleischer JG, Wasan KM, Brocks DR. The effect of experimental hyperlipidemia on the stereoselective tissue distribution, lipoprotein association and microsomal metabolism of (+/-)-halofantrine. J Pharm Sci. 2009;98:2516-28.

46. Shayeganpour A, Lee SD, Wasan KM, Brocks DR. The influence of hyperlipoproteinemia on in vitro distribution of amiodarone and desethylamiodarone in human and rat plasma. Pharm Res. 2007;24:672-8.

47. Kobuchi S, Fukushima K, Shibata M, Ito Y, Sugioka N, Takada K. Pharmacokinetics of clomipramine, an antidepressant, in poloxamer 407-induced hyperlipidaemic model rats. J Pharm Pharmacol. 2011;63:515-23.

48. Gershkovich P, Fanous J, Qadri B, Yacovan A, Amselem S, Hoffman A. The role of molecular physicochemical properties and apolipoproteins in association of drugs with triglyceride-rich lipoproteins: in-silico prediction of uptake by chylomicrons. J Pharm Pharmacol. 2009;61:31-9.

49. Dehouck B, Fenart L, Dehouck MP, Pierce A, Torpier G, Cecchelli R. A new function for the LDL receptor: transcytosis of LDL across the blood-brain barrier. J Cell Biol. 1997;138:877-89.

50. Yamauchi K, Tozuka M, Nakabayashi T, Sugano M, Hidaka H, Kondo Y, Katsuyama T. Apolipoprotein $\mathrm{E}$ in cerebrospinal fluid: relation to phenotype and plasma apolipoprotein E concentrations. Clin Chem. 1999;45:497-504.

51. Peter H, Tabrizian S, Hand I. Serum cholesterol in patients with obsessive compulsive disorder during treatment with behavior therapy and SSRI or placebo. Int J Psychiatry Med, 2000;30:27-39.

52. de Zwaan M, Nutzinger DO. Effect of fluvoxamine on total serum cholesterol levels during weight reduction. J Clin Psychiatry, 1996;57:346-348. 